\title{
A field test of the effects of megafaunal burrows on benthic chamber measurements of sediment-water solute fluxes
}

\author{
D. J. Hughes ${ }^{1, *}$, R. J. A. Atkinson ${ }^{2}$, A. D. Ansell ${ }^{1}$ \\ 'Centre for Coastal and Marine Sciences, Dunstaffnage Marine Laboratory, PO Box 3, Oban, Argyll PA34 4AD, Scotland, UK \\ ${ }^{2}$ University Marine Biological Station, Millport, Isle of Cumbrae KA28 0EG, Scotland, UK
}

\begin{abstract}
Benthic chambers are widely used in biogeochemical studies of marine sediments, but it is not known whether sediment-water solute fluxes recorded using such apparatus will be affected by the presence of a megafaunal burrow opening in the enclosed area of sea floor. We investigated this question in a shallow sea loch using simple benthic chambers deployed by divers over 2 contrasting burrow types, those of the mud-shrimp Callianassa subterranea and of the echiuran worm Maxmuelleria lankesteri. Fluxes of dissolved oxygen, manganese (II) and nutrients were measured over an 18 to $25 \mathrm{~h}$ incubation period and compared with those recorded over nearby sediment lacking megafaunal burrow openings. Chambers enclosing $C$. subterranea burrows recorded a significantly higher efflux of phosphate than controls, and efflux of ammonium was also consistently (though non-significantly) greater over burrows. C. subterranea burrows had no detectable effect on any other measured flux. Chambers enclosing $M$. lankesteri burrow openings differed from controls only in showing a significantly higher efflux of nitrate. This nitrate effect was particularly marked over $M$. lankesteri ejecta mounds, suggesting that these features may be localized sites of enhanced nitrification. Ranges of variation were high for all measured parameters, indicating that at this site, data from a single chamber incubation would be unlikely to unambiguously signify the presence of an identifiable megafaunal burrow opening. Spatial heterogeneity in solute flux rates illustrates the need to maximize replication in field studies using benthic chambers
\end{abstract}

KEY WORDS: Benthic chamber · Burrows - Callianassa $\cdot$ Maxmuelleria $\cdot$ Sea loch $\cdot$ Solute flux

\section{INTRODUCTION}

Benthic flux chambers have become important tools for the in situ measurement of solute exchanges across the sediment-water interface. The technique, employing a variety of chamber designs (Malan \& McLachlan 1991), has been applied both in coastal waters and in the deep ocean. Where depths are sufficiently shallow, chambers can be deployed by divers (e.g. Rutgers van der Loeff et al. 1984, Anderson et al. 1986, Barbanti et al. 1992). Chambers are also now frequently incorporated into the design of autonomous landing vehicles (Tengberg et al. 1995) and have been used in a number

•E-mail: djhu@dml.ac.uk of deep-sea studies (e.g. Berelson \& Hammond 1986, Jahnke \& Christiansen 1989, Aller et al. 1998).

Bioturbation by the benthic infauna is known to have a major influence on sediment-water fluxes of oxygen, nutrients and metals (Aller 1982, 1988), and several studies have explicitly considered the effects of faunal activity on the results obtained from benthic chamber deployments (Rutgers van der Loeff et al. 1984, Barbanti et al. 1992, Clavero et al. 1992, Forja \& GómezParra 1998). In these cases, attention has focused on animals in the macrofaunal size range, which are typically most abundant in the uppermost few centimetres of the sediment. However, many marine sediments also support a range of larger organisms occupying complex and long-lasting burrows which penetrate the substratum to much greater depths, extending in 
extreme cases to over $3 \mathrm{~m}$ below the surface (Pemberton et al. 1976). The burrowing 'megafauna' includes groups such as the thalassinidean crustaceans and echiuran worms (Atkinson 1986, Nickell et al. 1995b), and it is now well-established that these large bioturbators have a powerful influence on sediment-water solute fluxes (Koike \& Mukai 1983, Waslenchuk et al. 1983, Forster \& Graf 1995, Ziebis et al. 1996). Megafaunal burrows are abundant in many marine sediments (e.g. Ziebis et al. 1996, Hughes \& Atkinson 1997) and contribute substantially to the topographic heterogeneity of the sea floor. In environments such as these, a remotely deployed benthic chamber would have a high probability of landing over a megafaunal burrow opening, but no study has yet considered the potential of these structures to affect the solute fluxes recorded using the chamber technique.

For an accurate interpretation of spatial heterogeneity in flux rates measured using benthic chambers, it is important to determine whether fluxes obtained over megafaunal burrow openings can be distinguished from those of the 'background' sediment, and, if so, whether different burrowers have species-specific effects. We addressed this question by targeted deployments of chambers over megafaunal burrows of known identity, and by comparing the results with those obtained from control deployments over adjacent sediment lacking burrow openings

\section{METHODS}

Study site and target species. The study was carried out in Loch Sween, western Scotland, a shallow sea loch with a substratum consisting largely of organicrich, fine muds (silt-clay content $>90 \%$ ). The study site $\left(56^{\circ} 1.4^{\prime} \mathrm{N}, 5^{\circ} 36.9^{\prime} \mathrm{W}\right)$ was located approximately $150 \mathrm{~m}$. offshore, in a water depth of 12 to $13 \mathrm{~m}$.

The muddy sediments of Loch Sween support a diverse community of burrowing megafauna (Nickell et al. 1995b). The target species, selected because of their local abundance and contrasting burrow form, were the thalassinidean mud-shrimp Callianassa subterranea (Montagu) and the echiuran worm Maxmuelleria lankesteri (Herdman). In muddy sea loch sediments C. subterranea constructs a complex burrow consisting of a lattice of subsurface galleries which may extend to a depth of over $80 \mathrm{~cm}$, connected to the surface by 2 or more vertical shafts (Atkinson \& Nash 1990, Nickell \& Atkinson 1995). One surface opening is usually at the centre of a small mound of ejected sediment. In this sediment type the animal is largely a subsurface deposit-feeder (Nickell \& Atkinson 1995).

The echiuran Maxmuelleria lankesteri inhabits a narrow, sinuous burrow in the form of an extended $U$
(Hughes et al. 1996). One of the 2 surface openings is at the apex of a conical or domed ejecta mound. The other opening lacks a mound and appears as a simple circular hole in the sediment surface. The burrow of this species may also reach over $80 \mathrm{~cm}$ depth (Nickell et al. 1995a) and typically a 60 to $80 \mathrm{~cm}$ horizontal distance exists between the surface openings (Hughes et al. 1999). $M$. lankesteri is a surface deposit-feeder, grazing the superficial sediment around either burrow opening with its extensible proboscis (Hughes et al. 1994).

Benthic chamber design. Chamber design was similar to that used on the Elinor benthic lander (Glud et al. $1995,1996)$. The transparent polycarbonate chamber had a $30 \times 30 \mathrm{~cm}$ square cross-section with rounded corners (Fig. 1). The basal edges were chamfered to facilitate penetration of the sediment. Total chamber height was $25 \mathrm{~cm}$. A flat, removable polycarbonate lid was secured in place by 8 stainless steel clips. The edge of the lid had a rubber O-ring to ensure a good seal with the chamber. The water inside the chamber was kept circulating by a 4-bar stirrer (bar length $9 \mathrm{~cm}$, diameter $1.3 \mathrm{~cm}$ ) driven by a geared, $12 \mathrm{~V} \mathrm{DC}$ motor (RS Components, Part No. 266991) held in a silicone fluid-filled housing. Power was supplied by sixteen $1.5 \mathrm{~V}$ industrial alkaline batteries in a sealed housing mounted in a plastic superstructure above the chamber lid (Fig. 1). The battery housing was linked to the stir-

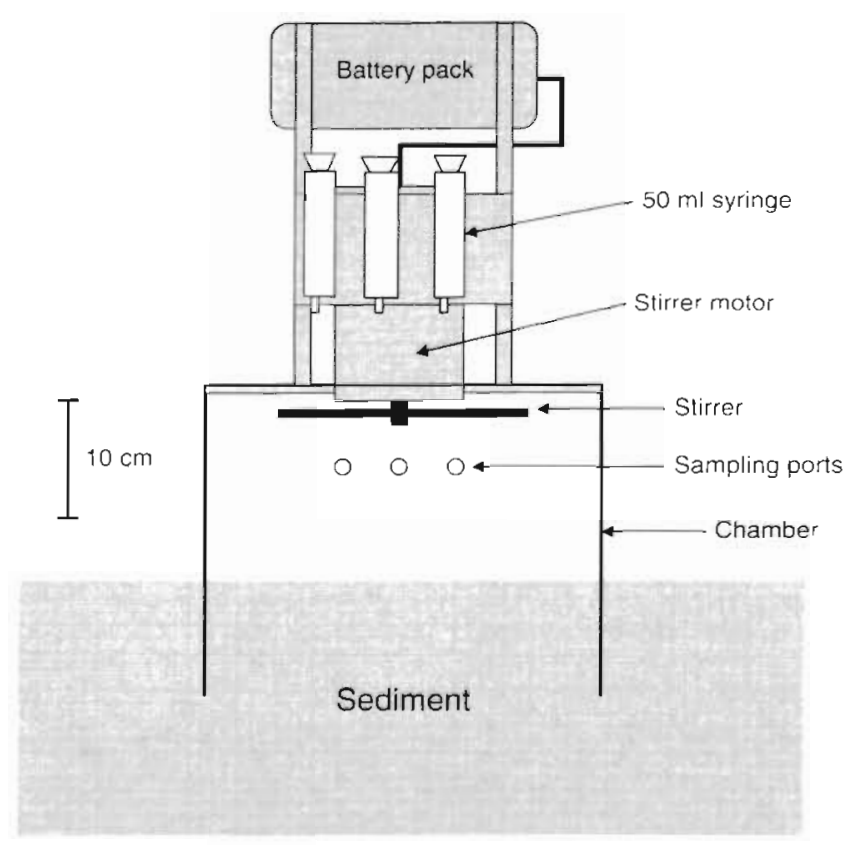

Fig. 1. Design of the diver-deployed benthic flux chambers used in. this study. For clarity, only 1 set of three $50 \mathrm{ml}$ syringes is shown, and the tubing connectors between the syringes and the sampling ports have been omitted 
rer motor by a cable with water-resistant 3-pin connectors. The stirrerwas set to rotate at $4 \mathrm{rpm}$, equivalent to approximately $5 \mathrm{~cm} \mathrm{~s}^{-1}$. It is important to note that this figure represents the circular movement rate of the stirrer arms, not the flow velocity at the sedimentwater interface, which was not measured.

The chambers were designed to be deployed by divers over selected areas of sea floor, and for the enclosed water to be sampled by manual extraction of $50 \mathrm{ml}$ volumes via syringe. Three sampling ports were present in each of 3 of the chamber side walls, each port being connected to a $50 \mathrm{ml}$ syringe by a short length of silicone rubber tubing ( $4 \mathrm{~mm}$ bore). The syringes were mounted in groups of 3 on panels bolted to the plastic superstructure supporting the battery housing (Fig. 1). Each group comprised 1 glass and 2 plastic syringes.

Chamber deployment. Five benthic chambers were available for use in this study. On-site, these were secured in lightweight metal frames and gently lowered to the sea bed from a small boat. Divers then removed the chambers from their deployment frames and detached the lid from each one. A diver then placed each chamber over a megafaunal burrow opening, or over a control area of sediment without burrow openings. Each chamber was put in place without its lid in order to minimize pressure wave-induced disturbance to the sediment surface. The $25 \mathrm{~cm}$-high chambers were carefully pushed into the sediment to a depth of $10 \mathrm{~cm}$, thus enclosing a water column $15 \mathrm{~cm}$ high. A lid was then fitted to each chamber and secured in place. The tubing connectors of the nine $50 \mathrm{ml}$ syringes on each chamber were then attached to the corresponding sampling ports in the chamber sides, the motor was switched on and the stirrer set in motion.

Water sampling. An initial set of water samples $(3 x$ $50 \mathrm{ml}$ syringes, 1 glass, 2 plastic) was taken from within each chamber immediately after completion of the deployment procedure described above. After being filled with $50 \mathrm{ml}$ of water from inside the chamber, each of the 3 syringes was disconnected from the chamber for recovery to the surface. A screw clamp on the syringe tubing was tightened to prevent any accidental loss of the sample during recovery. A port in the chamber lid, connected to $50 \mathrm{~cm}$ of narrowbore tubing (to minimize diffusive exchange) allowed an inflow of external water to compensate for the volumes removed in each syringe sample. At the time of initia] chamber deployment, $15 \times 50 \mathrm{ml}$ syringe samples (5 glass, 10 plastic) were collected external to the chambers for analysis of solute concentrations in the ambient near-bottom water. The temperature of the near-bottom water was taken from a mercury thermometer carried by a diver. Salinity was measured in the laboratory (by hydrometer) using the external water syringe samples.

The contents of each chamber were sampled again at 18 to 24 and 43 to $45 \mathrm{~h}$ after initial deployment. At each sampling interval $3 \times 50 \mathrm{ml}$ volumes of water ( 1 glass, 2 plastic syringes) were extracted from each chamber.

Solute analysis. The water samples taken from the chambers at each sampling interval were analyzed for dissolved oxygen, soluble manganese (II) $\left(\mathrm{Mn}^{2+}\right)$ and nutrients. The samples collected in glass syringes were fixed immediately on return to the shore by injection of $0.5 \mathrm{ml}$ manganese (II) chloride and $0.5 \mathrm{ml}$ alkaline iodide, returned to the laboratory in a sealed cool box. and analyzed for dissolved oxygen by Winkler titration (Grasshoff 1983), with visual determination of the endpoint. Oxygen measurements were carried out approximately $6 \mathrm{~h}$ after sample collection.

Water samples intended for analysis of soluble manganese (II) were passed through an in-line filter (Whatman $G F / F$ ), and a subsample was diluted 10 -fold with $55 \mathrm{mM}$ nitric acid. Manganese (II) concentrations in the acidified subsamples were measured by graphite furnace atomic absorption spectrophotometry (Pye Unicam Model SP9).

Samples intended for nutrient analysis were passed through an in-line filter (Whatman GF/C) and fixed by addition of $15 \mu$ l saturated mercuric chloride solution (Kirkwood 1992). Nutrient measurements were made approximately 1 wk after sample collection using a Lachat Quickchem 8000 autoanalyzer. Samples collected in 1996 were analyzed for nitrate, phosphate and silicate, those collected in 1997 were analyzed for these 3 nutrients plus ammonium.

Solute flux calculations. Solute flux rates were calculated using the within-chamber concentrations measured at the first 2 sampling intervals (i.e. immediately after initial deployment and after 18 to $24 \mathrm{~h}$ incubation). Allowance was made for the small inflow of external water that took place as each syringe sample was withdrawn from the chamber. The free water volume enclosed within a chamber was estimated using the known cross-sectional area $\left(880 \mathrm{~cm}^{2}\right)$ and the height of the chamber above the substratum. Chamber height was nominally $15 \mathrm{~cm}$, actual heights were estimated using a graduated scale (precision $0.5 \mathrm{~cm}$ ) on the chamber side. An adjustment was made for the volume occupied by the stirrer. On each deployment, topographic irregularities (chiefly ejecta mounds) in the patch of sea floor enclosed by a chamber were noted, and their dimensions measured. Any enclosed mound was equated to the closest simple geometric solid (complete or truncated cone), its volume calculated, and the estimated water volume inside the chamber reduced accordingly. 
Table 1 Temperature, salinity and dissolved oxygen concentration of near-bottom water at the Loch Sween study site during the months in which benthic chamber experiments were conducted. Oxygen values are means $( \pm S D)$ of 5 replicate $50 \mathrm{ml}$ water samples

\begin{tabular}{|lrccc|}
\hline Date & $\begin{array}{c}\text { Temp. } \\
\left({ }^{\circ} \mathrm{C}\right)\end{array}$ & $\begin{array}{c}\text { Salinity } \\
(\mathrm{ppt})\end{array}$ & $\begin{array}{c}\mathrm{O}_{2} \text { concentration } \\
\left.(\mu \mathrm{mol})^{-1}\right)\end{array}$ & $\begin{array}{c}\% \mathrm{O}_{2} \\
\text { saturation }\end{array}$ \\
\hline 14 May 96 & 9 & 35 & $205.4 \pm 26.1$ & $72.3 \pm 8.9$ \\
11 Jun 96 & 12 & 34 & $157.5 \pm 23.0$ & $57.9 \pm 8.5$ \\
9 Jul 96 & 13 & 34 & $179.4 \pm 9.9$ & $67.5 \pm 3.7$ \\
6 Aug 96 & 14 & 35 & $170.4 \pm 15.0$ & $65.8 \pm 5.8$ \\
10 Sep 96 & 14 & 34 & $97.3 \pm 17.4$ & $37.3 \pm 6.6$ \\
11 Mar 97 & 8 & 33 & $162.1 \pm 21.0$ & $54.2 \pm 7.0$ \\
15 Apr 97 & 9 & 35 & $165.9 \pm 24.8$ & $57.6 \pm 8.6$ \\
10 Jun 97 & 13 & 35 & $192.5 \pm 24.2$ & $72.7 \pm 9.1$ \\
16 Jul 97 & 14 & 35 & $177.0 \pm 11.7$ & $68.4 \pm 4.5$ \\
\hline
\end{tabular}

\section{RESULTS}

Field deployments were carried out monthly from May to September 1996, and in March, April, June and July 1997. Because of the small number of benthic chambers available, replication of results was maximized by focusing each deployment on 1 of the 2 target species. Callianassa subterranea burrows were studied in May to June 1996 and March to April 1997. Deployments made in July to September 1996 and June to July 1997 were devoted to Maxmuelleria lankesteri.
Table 1 lists the temperature, salinity and dissolved oxygen concentration of the near-bottom water at the study site during the period of each chamber experiment. Temperatures were in the range 8 to $12^{\circ} \mathrm{C}$ in those months in which Callianassa subterranea was studied, and 13 to $14^{\circ} \mathrm{C}$ during deployments over Maxmuelleria lankesteri burrows. Salinity was close to full seawater strength at all times. The near-bottom water was always hypoxic to some degree, with the lowest percentage saturation values recorded in September 1996

\section{Callianassa subterranea}

On each of the 4 deployments devoted to this species, 3 chambers were placed over Callianassa subterranea burrows, with 2 control chambers placed over sediment lacking surface features created by burrowing megafauna. On each occasion, the maximum distance between any of the 5 chambers was about $10 \mathrm{~m}$. The criterion for selecting particular C. subterranea burrows for experiments was that all surface features of each target system could be enclosed within a chamber. Typically, the surface features consisted of 1 small (5 to $12 \mathrm{~cm}$ diameter) ejecta mound, with an adjacent pit or burrow opening present in $50 \%$ of cases. Six of the ejecta mounds had an apical burrow opening occluded by coarse, pelletized sediment. These struc- a) Callianassa: March 97

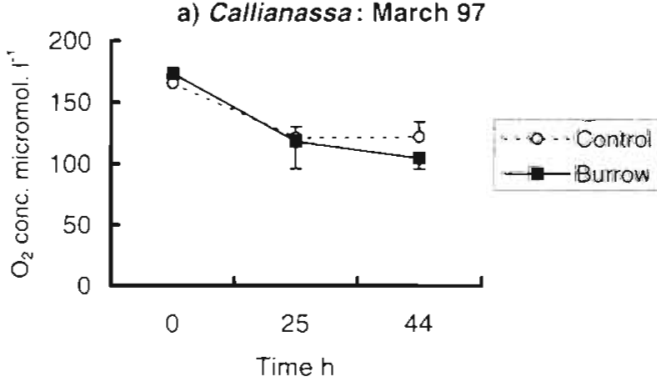

c) Callianassa: May 96

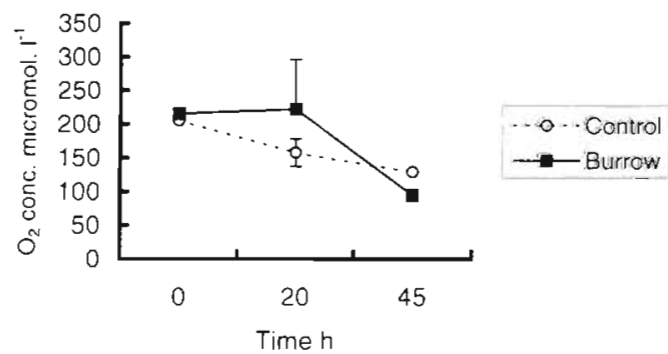

b) Callianassa: April 97

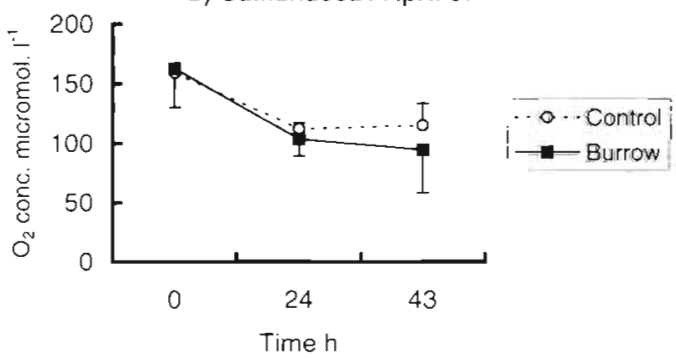

d) Callianassa: June 96

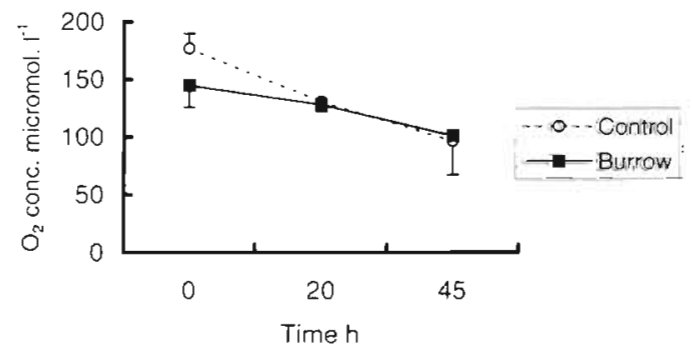

Fig. 2. Changes in dissolved oxygen concentration with time in benthic chambers placed over burrows of Callianassa subterranea or over nearby unburrowed sediment, in 4 separate experiments. Data points are mean values with upper or lower SD (some error bars omitted for clarity). In each experiment, $\mathrm{n}=3$ chambers over burrows, $\mathrm{n}=2$ controls 


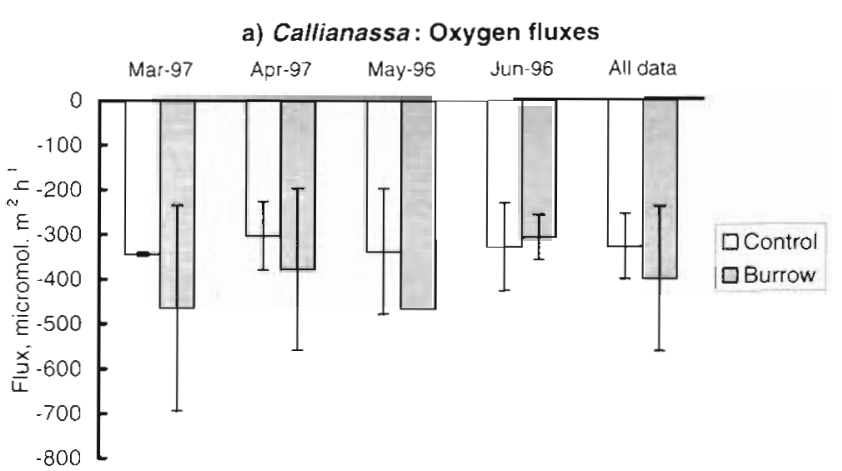

b) Callianassa: Manganese (II) fluxes

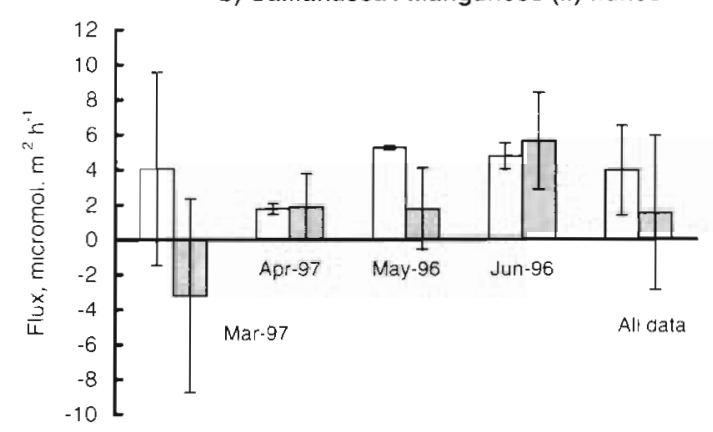

口Control: aBurrow

Fig. 3. Fluxes of (a) dissolved oxygen and (b) manganese (II) in benthic chambers placed over burrows of Callianassa subterranea or over nearby unburrowed sediment. Bars represent means \pm SD Positive mean values indicate efflux from the sediment, and negative mean values uptake by the sediment. Means are presented for each individual monthly experiment, and for all data pooled. Sample sizes in each individual experiment are as outlined in Fig. 2. For pooled means, $n=8$ controls, $\mathrm{n}=12$ burrows

tures were termed 'percolation mounds' by Nickell \& Atkinson (1995). In no case was there any observed change in the number, size or appearance of the surface features enclosed in a chamber over the deployment period.

The enclosed water did not become anoxic in either control chambers or those deployed over Callianassa subterranea burrows (Fig. 2). Final dissolved oxygen concentrations (after 43 to $45 \mathrm{~h}$ incubation) were in the range 52.9 to $136.7 \mu \mathrm{mol} \mathrm{l}^{-1}$, equivalent to $18.4-50.3 \%$ saturation. Over the full incubation period the change in oxygen concentration with time was strongly nonlinear in at least 2 of the experiments (Fig. 2a,b), justifying the decision to use only the data from the first 20 to $25 \mathrm{~h}$ to calculate solute flux rates.

Mean sediment oxygen uptake rate over Callianassa subterranea burrows was higher than the corresponding control means in 3 of the 4 mo (Fig. 3a). The mean for burrow chambers was also higher when all data a) Callianassa: Phosphate fluxes

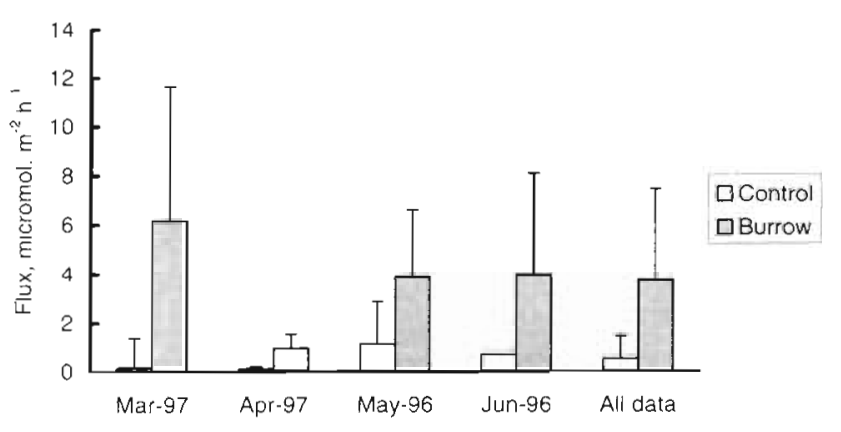

b) Callianassa: Silicate fluxes

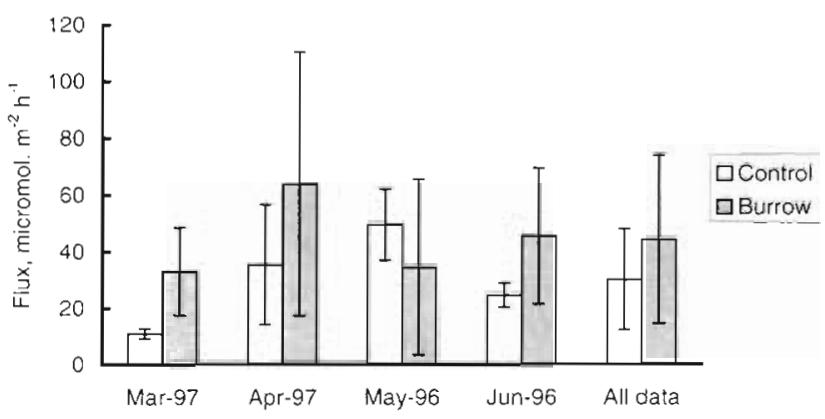

Fig. 4. Fluxes of (a) phosphate and (b) silicate in benthic chambers placed over burrows of Callianassa subterranea or over nearby unburrowed sediment. Bars represent means \pm SD Positive mean values indicate efflux from the sediment, negative mean values uptake by the sediment. Means are presented for each individual monthly experiment, and for all data pooled. Sample sizes in each individual experiment are as outlined in Fig, 2. For pooled means, $n=8$ controls, $\mathrm{n}=12$ burrows

were pooled, but the difference between this and the pooled control mean was non-significant ( 2 -sample $t$ test, $\mathrm{p}=0.25$ ). Fluxes of soluble manganese (II) were highly variable, and there was no consistent trend in the differences between burrow and control means (Fig. 3b). When all data were pooled, a greater mean efflux was recorded from controls compared with burrow chambers, but the difference was non-significant (2-sample $t$-test, $\mathrm{p}=0.14$ ).

Mean efflux of phosphate from the sediment was always higher in chambers enclosing Callianassa subterranea burrows (Fig. $4 \mathrm{a}$ ), and the difference between pooled burrow $\left(3.74 \pm 3.70 \mu \mathrm{mol} \mathrm{m}{ }^{-2} \mathrm{~h}^{-1}\right)$ and control $\left(0.53 \pm 0.92 \mu \mathrm{mol} \mathrm{m}{ }^{-2} \mathrm{~h}^{-1}\right)$ means was statistically significant $(2$-sample $t$-test, $\mathrm{p}<0.05)$. Silicate efflux was higher over burrows in 3 of the 4 mo (Fig. 4 b), but there was no significant difference between pooled means for burrow and control chambers (2-sample t-test, $\mathrm{p}=$ $0.20)$. 
a) Callianassa: Nitrate fluxes

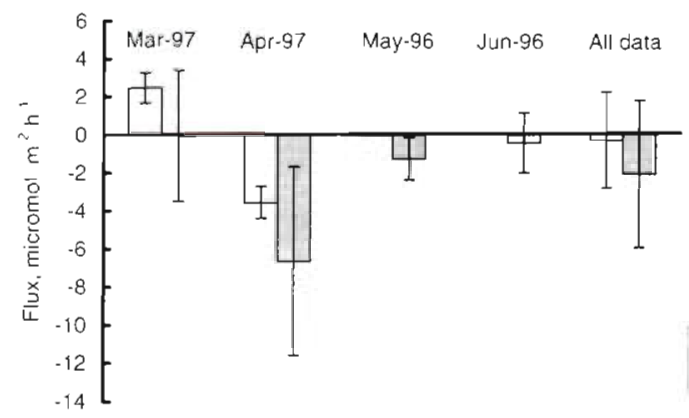

b) Callianassa: Ammonium fluxes

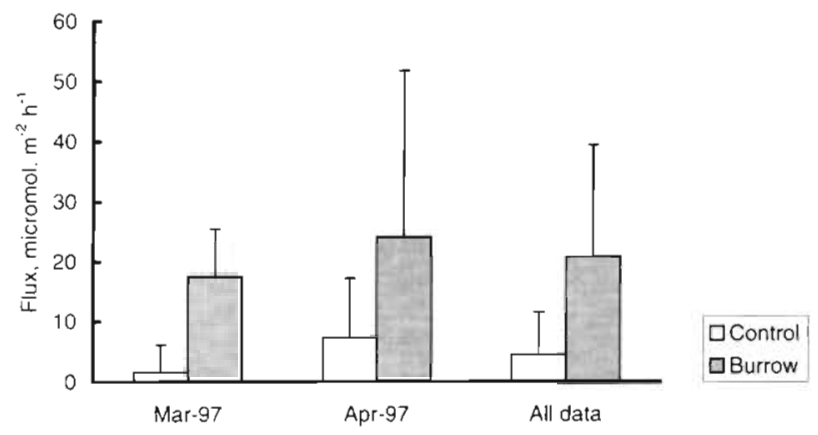

Fig. 5. Fluxes of (a) nitrate and (b) ammonium in benthic chambers placed over burrows of Callianassa subterranea or over nearby unburrowed sediment. Bars represent means \pm SD. Positive mean values indicate efflux from the sediment, negative mean values uptake by the sediment. Means are presented for each individual monthly experiment, and for all data pooled. Sample sizes in each individual experiment are as outlined in Fig. 2. For pooled nitrate means, $\mathrm{n}=8$ controls, $\mathrm{n}=12$ burrows. For pooled ammonium means, $n=4$ controls, $n=6$ burrows

Chambers normally recorded a strong net efflux of ammonium and a small decrease in nitrate concentration (Fig. 5). The uptake of nitrate was consistently greater in chambers enclosing burrows (Fig. 5a), but the difference from control chambers was not statistically significant when pooled means for the 2 groups were compared (2-sample $t$-test, $p=0.24)$. In both March and April 1997, the mean efflux of ammonium in burrow chambers was much higher than the corresponding control means (Fig. 5b). Pooling data from the 2 experiments, the burrow mean $\left(20.80 \pm 18.55 \mu \mathrm{mol} \mathrm{m} \mathrm{m}^{-2} \mathrm{~h}^{-1}\right)$ was approximately 5 times higher than the control ( 4.51 $\pm 7.07 \mu \mathrm{mol} \mathrm{m} \mathrm{m}^{-2} \mathrm{~h}^{-1}$ ), but the variability within the burrow values (indicated by the large standard deviation of the pooled mean) meant that this difference failed to reach statistical significance $(2$-sample $t$-test, $\mathrm{p}=0.10)$. a) Maxmuelleria: June 97

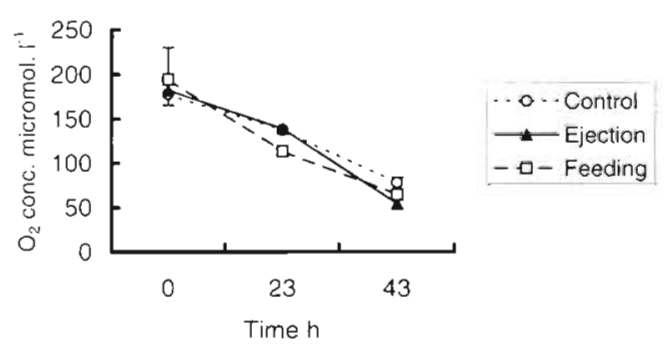

c) Maxmuelleria: August 96

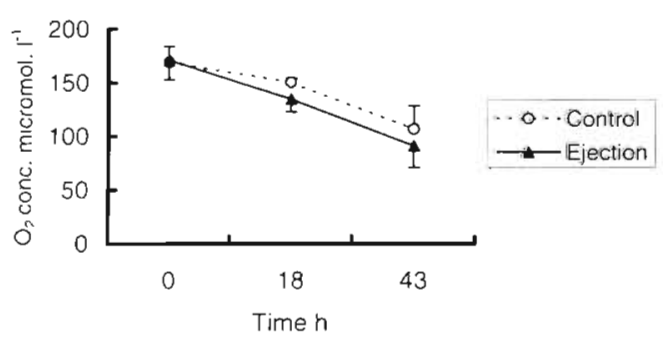

b) Maxmuelleria: July $96+97$

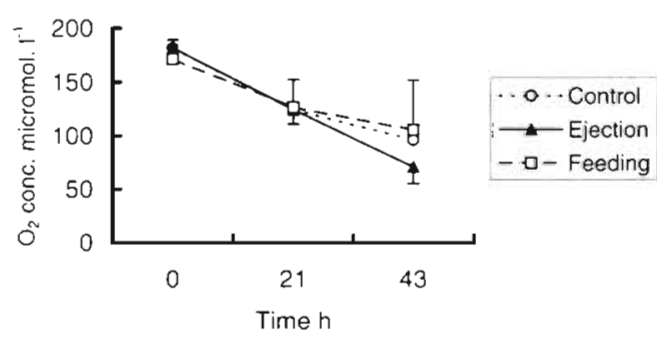

d) Maxmuelleria : September 96

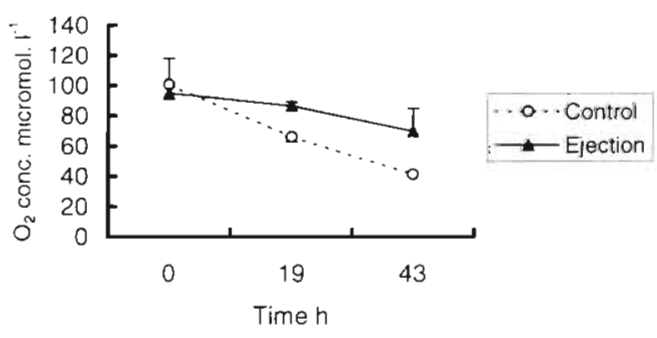

Fig. 6. Changes in dissolved oxygen concentration with time in benthic chambers placed over burrow openings of Maxmuelleria lankesteri or over nearby unburrowed sediment, in 5 separate experiments, with data from July 1996 and July 1997 pooled. Data points are mean values with upper or lower SD (some error bars omitted for clarity). Sample sizes are $\mathrm{n}=1$ control, $\mathrm{n}=2$ ejection sites, $\mathrm{n}=2$ feeding sites (June 1997); $\mathrm{n}=2$ controls, $\mathrm{n}=3$ ejection sites (August 1996 and September 1996), $\mathrm{n}=3$ controls, $\mathrm{n}=5$ ejection sites, $n=2$ feeding sites (July 1996 and 1997) 
a) Maxmuelleria: Oxygen fluxes

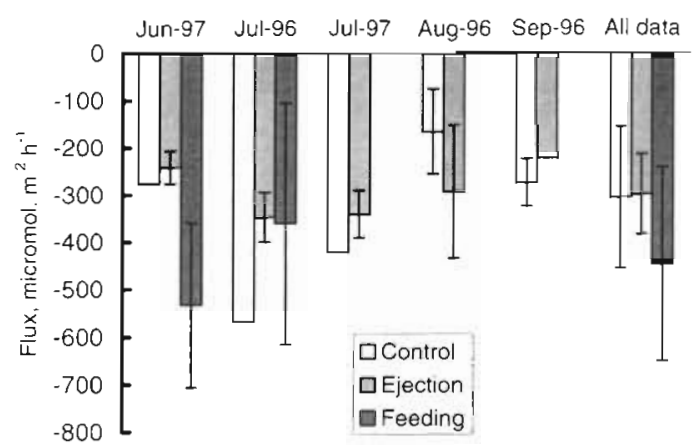

b) Maxmuelleria: Manganese (II) fluxes

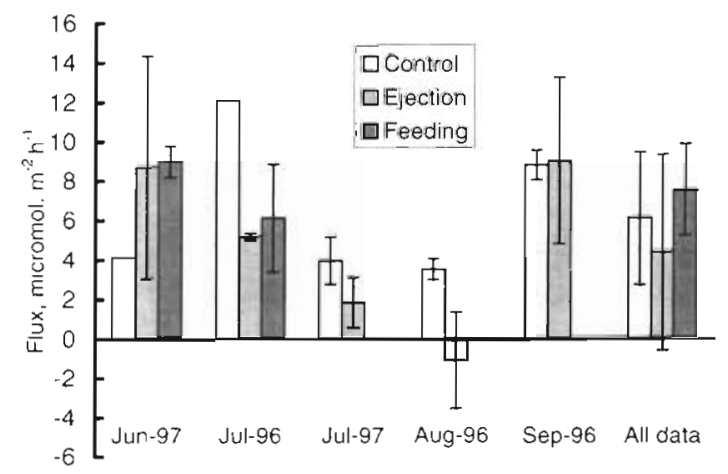

Fig. 7. Fluxes of (a) dissolved oxygen and (b) manganese (II) in benthic chambers placed over burrow openings of $M$ axmuelleria lankesteri or over nearby unburrowed sediment. Bars represent means \pm SD. Positive mean values indicate efflux from the sediment, negative mean values uptake by the sediment. Means are presented for each individual monthly experiment, and for all data pooled. Sample sizes in each individual experiment are as outlined in Fig. 6 . For pooled means, $n=8$ controls, $n=13$ ejection sites, $n=4$ feeding sites

\section{Maxmuellería lankesteri}

In August 1996, September 1996 and July 1997, 3 chambers were deployed over Maxmuelleria lankesteri ejecta mounds, with the remaining 2 used as controls. In July 1996 and June 1997, 2 chambers were placed over ejecta mounds and 2 others over $M$. lankesteri feeding sites, with the remaining chamber in each month used as a control.

The ejecta mounds used for chamber deployments were typically 25 to $30 \mathrm{~cm}$ in diameter and 7 to $8 \mathrm{~cm}$ high in the centre, with a small $(\sim 1 \mathrm{~cm}$ diameter $)$ apical burrow opening. Feeding sites lacked mounds, and with 1 exception also lacked a burrow opening at the time of the chamber deployments (the feeding openings of Maxmuelleria lankesteri burrows are occluded by sediment for much of the time). None of the selected mounds or feeding sites changed in appearance during the chamber incubations. In particular, no fresh material was seen to be vented from any of the ejecta mounds.

As in the Callianassa subterranea experiments, the chamber contents remained oxic at the end of the incubation period (Fig. 6). Final dissolved oxygen concen-

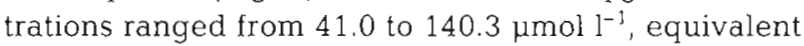
to $15.7-52.7 \%$ saturation. The declines in oxygen concentration over time showed a more consistent linearity than those recorded in the $C$. subterranea experiments. However, in order to maximize comparability of results, flux rates were calculated using the data from the initial 18 to $23 \mathrm{~h}$ of incubation.

Comparing ejecta mounds, feeding sites and control sediment, no consistent pattern emerged in oxygen uptake rates (Fig. $7 \mathrm{a}$ ), and the differences between pooled means were non-significant (1-way ANOVA, $p=0.17$ ). A small efflux of soluble manganese (II) was observed in almost all cases, but with no consistent trend in the values recorded from mounds, feeding sites and controls (Fig. 7b). Pooled means for the 3 groups were very similar and did not differ significantly (1-way ANOVA, $p=0.59$ ). Data for phosphate (Fig. 8a) and silicate (Fig. 8b) efflux also showed no significant effects of chamber content (1-way ANOVA, $p=0.48$ for phosphate, $\mathrm{p}=0.92$ for silicate)

In contrast to the Callianassa subterranea experiments, nitrate concentrations typically increased over the incubation period (Fig. 9a). Mean nitrate efflux rates over Maxmuelleria lankesteri ejecta mounds were greater than control values in all 5 experiments. Efflux rates from feeding sites in June 1997 and July 1996 fell between those for mounds and controls. When all data were considered, mean nitrate efflux rates for ejecta mounds $\left(5.17 \pm 4.20 \mu \mathrm{mol} \mathrm{m} \mathrm{m}^{-2} \mathrm{~h}^{-1}\right)$ and feeding sites $\left(1.87 \pm 1.96 \mu \mathrm{mol} \mathrm{m} \mathrm{m}^{-2} \mathrm{~h}^{-1}\right)$ were both higher than the control mean $10.24 \pm 0.95 \mu \mathrm{mol} \mathrm{m} \mathrm{m}^{-2}$ $\mathrm{h}^{-1}$ ). The differences between the 2 burrow features and the control mean were highly significant (1-way ANOVA, $p<0.01$, and Tukey's pairwise comparisons). Ammonium efflux rates were much higher in absolute terms than those for nitrate (Fig. 9b), but there were no significant differences between the 3 chamber groups (1-way ANOVA, $\mathrm{p}=0.92$ ).

\section{DISCUSSION}

\section{Reliability of benthic chamber flux measurements}

Sediment-water solute fluxes have not previously been measured in Loch Sween. Data from other Scottish sea lochs can be used to assess the reliability of the 
a) Maxmuelleria: Phosphate fluxes

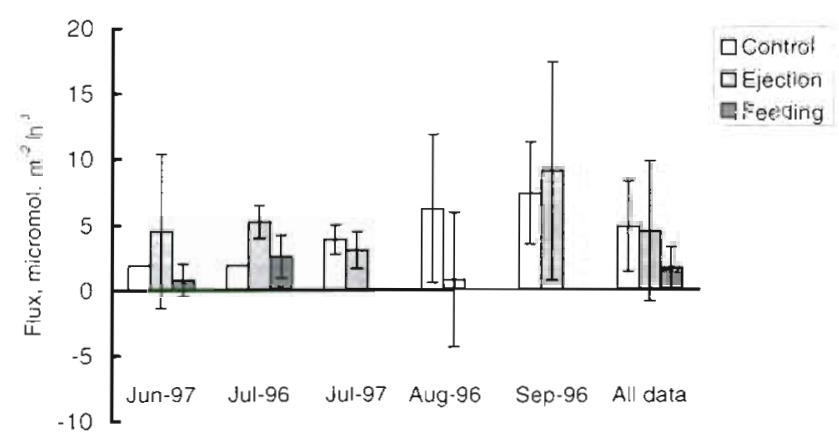

b) Maxmuelleria : Silicate fluxes

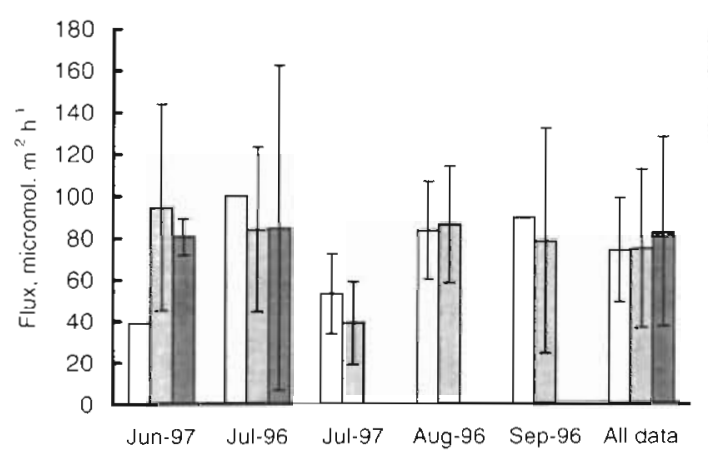

Fig. 8. Fluxes of (a) phosphate and (b) silicate in benthic chambers placed over burrow openings of Maxmuelleria lankesteri or over nearby unburrowed sediment. Bars represent means \pm SD. Positive mean values indicate efflux from the sediment, negative mean values uptake by the sediment. Means are presented for each individual monthly experiment, and for all data pooled. Sample sizes in each individual experiment are as outlined in Fig. 6. For pooled means, $n=8$ controls, $\mathrm{n}=13$ ejection sites, $\mathrm{n}=4$ feeding sites

flux rates reported here, though comparisons must be made with caution given the diversity of hydrographic regimes and degrees of organic input found among these water bodies (Edwards \& Sharples 1986, Howson et al. 1994). In Loch Sween, oxygen uptake rates in control chambers (i.e. avoiding any possible megafaunal burrow effects) were in the range 103.3 to 567.4 umol m $\mathrm{m}^{-2} \mathrm{~h}^{-1}$, equivalent to $2.5-13.6 \mathrm{mmol} \mathrm{m} \mathrm{m}^{-2} \mathrm{~d}^{-1}$. Overnell et al. (1995) compiled data from several sea lochs and cited uptake rates between 4.7 and 24.6 $\mathrm{mmol} \mathrm{m} \mathrm{m}^{-2} \mathrm{~d}^{-1}$, while data in the range 8 to $24 \mathrm{mmol} \mathrm{m}-2$ $\mathrm{d}^{-1}$ were recorded from Lochs Goil, Fyne and Etive by Overnell et al. (1996). The Loch Sween data fall at the lower end of these published ranges but are entirely comparable in magnitude. In Loch Linnhe, nitrate showed a period of efflux during March, followed by influx in April to May and efflux again during June, while silicate efflux increased markedly after the spring plankton bloom (Overnell et al. 1995). Both patterns were found in the Loch Sween control chamber data, and the absolute values of the fluxes were also quite comparable. Overnell et al. (1996) found that measured manganese (II) fluxes in sediment from 2 sea lochs were so variable as to raise doubts about the reliability of the data. This precludes comparison with the Loch Sween control data, which showed far less variability.

A confounding factor in the comparison of flux rates from different lochs is that most existing data are derived from laboratory core incubations rather than in situ benthic chamber experiments. The work of Davies (1975) in Loch Thurnaig allows a more direct comparison, although the annular chamber he used was very different to the design employed here. With an annular flow velocity of $3 \mathrm{~cm} \mathrm{~s}^{-1}$, oxygen uptake rates in the approximate range of 130 to $780 \mu \mathrm{mol} \mathrm{m} \mathrm{m}^{-2} \mathrm{~h}^{-1}$ were

a) Maxmuelleria: Nitrate fluxes

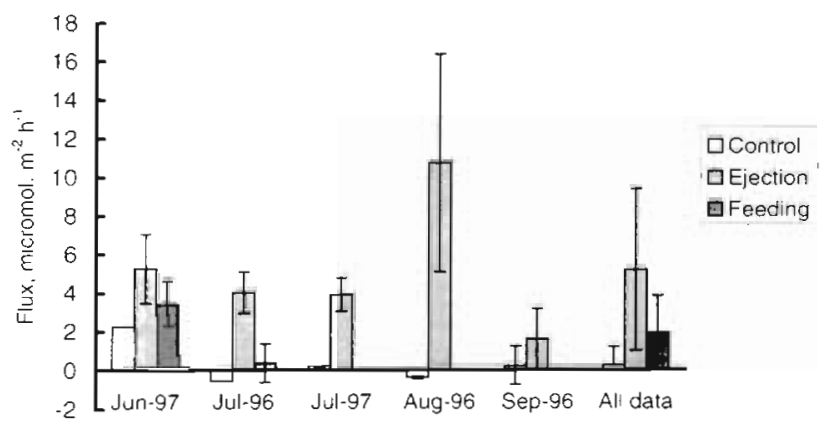

b) Maxmuelleria: Ammonium fluxes

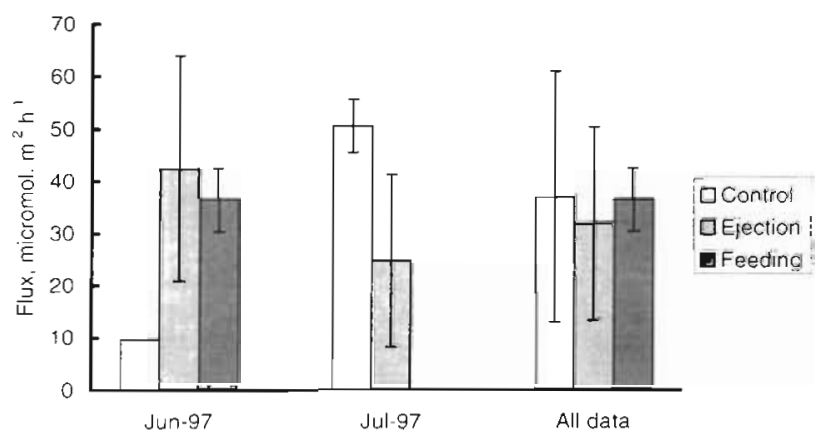

Fig, 9. Fluxes of (a) nitrate and (b) ammonium in benthic chambers placed over burrow openings of Maxmuelleria lankesteri or over nearby unburrowed sediment. Bars represent means $\pm \mathrm{SD}$. Positive mean values indicate efflux from the sediment, negative mean values uptake by the sediment. Means are presented for each individual monthly experiment, and for all data pooled. Sample sizes in each individual experiment are as outlined in Fig. 6. For pooled nitrate means, $\mathrm{n}=8$ controls, $\mathrm{n}=13$ ejection sites, $\mathrm{n}=4$ feeding sites. For pooled ammonium means, $n=3$ controls, $n=5$ ejection sites, $n=2$ feeding sites 
recorded, figures very close to those obtained in Loch Sween. Ammonium efflux in Loch Thurnaig rose slightly from March to June, then showed a very steep increase in July. The same pattern was seen in the control data from Loch Sween, although the absolute values for ammonium flux were much higher (e.g. in July, approximately $5.60 \mu \mathrm{mol} \mathrm{m}^{-2} \mathrm{~h}^{-1}$ in Loch Thurnaig, compared with $50.58 \mu \mathrm{mol} \mathrm{m} \mathrm{m}^{-2} \mathrm{~h}^{-1}$ in Loch Sween).

Although caution is required in comparing data from different sea lochs, obtained using different experimental techniques, the figures presented here for Loch Sween 'background' sediment (i.e. lacking megafaunal burrow openings) are sufficiently similar to those reported from other sea lochs as to provide no grounds for doubting their reliability.

\section{Heterogeneity of within-treatment means}

Disregarding for the moment any potential additive effects of megafaunal burrow openings, a number of factors will contribute to the wide ranges of variation associated with the mean values for each treatment group. Small sample sizes (maximum 3 chambers per treatment in each deployment) were imposed by the number of chambers available. Error bars for mean fluxes pooled across deployments are wide because the values are averaged across monthly changes in temperature and other environmental factors. Field observation of the depth of chamber penetration allowed estimation of free water volume with a relatively coarse precision of $1.0 \mathrm{~cm}^{3}$, so that some measurement error was involved in the calculation of solute concentrations. Finally, all chamber flux measurements, whether over megafaunal burrow openings or 'background' sediment, include the contribution of the sediment macrofauna, which undoubtedly has a major influence on sediment-water exchanges (Aller 1982). A detailed survey of spatial patchiness in the macrofauna of the study site was beyond the scope of this work, but this factor may also explain some of the variability within treatment groups in each deployment.

\section{Effects of megafaunal burrow openings on measured solute fluxes}

\section{Callianassa subterranea}

Enclosed Callianassa subterranea burrows had no statistically significant effect on measured fluxes of oxygen, manganese (II), silicate or nitrate. C. subterranea burrows were associated with a significantly increased efflux of phosphate and also with a consistently increased efflux of ammonium, although the effects on this last parameter did not reach statistical significance.

Nickell (1992) recorded enhanced concentrations of ammonium and phosphate in the water filling burrows of Callianassa subterranea in sea loch sediments. Ammonium and phosphate enrichment also occurs in the burrows of some other thalassinidean species (Koike \& Mukai 1983, Waslenchuk et al. 1983), although Ziebis et al. (1996) found that passive advective ventilation of $C$. truncata burrows in a sandy sediment was sufficiently intense to prevent build-up of ammonium. Enclosure of all surface openings within a benthic chamber would not prevent active ventilation of the burrow by its occupant, so that Nickell's (1992) findings are in accord with the results presented here. The mean burrow irrigation rate of C. subterranea in a quaria was estimated as $36.3 \mathrm{~cm}^{3} \mathrm{~h}^{-1}$ (Nickell 1992). It is uncertain to what extent aquarium measurements are representative of activity in nature, but at this rate an animal would circulate only about $6.6 \%$ of the water enclosed in the chamber (approx. $13200 \mathrm{~cm}^{3}$ ) through its burrow during a $24 \mathrm{~h}$ experimental period. Active ventilation by the occupant may have been supplemented (or exceeded in importance) by passive flushing of the burrow induced by the chamber stirring process. The internal hydrodynamics of the chamber design used in this study $(30 \times 30 \mathrm{~cm}$ square cross-section with rounded corners, stirred by 4 cylindrical rods) have been intensively studied, with much effort devoted to measuring the effects of stirring rate on the distribution of radial pressure gradients and the thickness of the diffusive boundary layer at the sedimentwater interface (Buchholtz-ten Brink et al. 1989, Huettel \& Gust 1992, Glud et al. 1995, 1996). Stirringinduced advective efflux of solutes from the centre of the enclosed area is likely to be negligible in clay-rich, impermeable muds such as those of Loch Sween (Huettel \& Gust 1992, Glud et al. 1995). However, the radial pressure gradient is likely to cause increased flushing of any U-shaped burrows enclosed within the chamber (Glud et al. 1995, 1996), and this factor may have operated in the C. subterranea deployments.

\section{Maxmuelleria lankesteri}

Burrow openings of Maxmuelleria lankesteri appeared not to significantly affect sediment-water fluxes of oxygen, manganese (II), phosphate, silicate or ammonium. This was the case irrespective of whether the enclosed opening formed the ejection or the feeding end of the burrow. There is little available information on the chemical environment of echiuran burrows, but one would expect the $M$. lankesteri burrow to be hypoxic and sulphide-enriched, given its deep penetration into 
anoxic, organically enriched sediments. Arp et al. (1992) found that these conditions prevailed in the burrow of Urechis caupo, although the ecology of this intertidal echiuran differs quite considerably from that of $M$. lankesteri. Major venting episodes involving expulsion of fluidized sediment occur on average only once every 48 h (Hughes et al. 1996), suggesting that other solutes (e.g. excretory ammonium) may also accumulate in the $M$. lankesteri burrow. The failure to detect any increased efflux of ammonium, phosphate, silicate or manganese (II) in burrow-enclosing chambers may stem from the fact that an echiuran would have been prevented from ventilating its burrow owing to the backpressure imposed by the chamber deployed over 1 opening (in contrast to the Callianassa subterranea experiments, in which all surface openings of each burrow were enclosed and water could be circulated within the chamber). The visual appearance of the $M$. lankesteri ejecta mounds confirmed that no sediment expulsion occurred during any of the chamber deployments. Stirring-induced flushing of the burrow should also be prevented by enclosure of 1 opening, so that the measured fluxes are likely to be purely diffusive.

In all 3 chamber groups (controls, feeding and ejection sites) most of the soluble nitrogenous material accumulated in the reduced form (ammonium). However, significantly higher effluxes of nitrate were recorded over burrow openings, particularly ejecta mounds, when compared with the 'background' sediment. This may indicate a difference in microbial populations, specifically in numbers of nitrifying bacteria, between 'background' and near-burrow sediment. If the ejecta mounds of Maxmuelleria lankesteri do act as localized 'hot-spots' of nitrate production, the species may indirectly play a significant role in the nitrogen cycle of its sea loch environment.

\section{Implications of results for future benthic chamber field studies}

The results presented here show that for certain solutes, chamber fluxes overlying burrow openings of Callianassa subterranea and Maxmuelleria lankesteri could be distinguished statistically from unburrowed controls. This is true irrespective of whether the causal factor underlying the burrow effect is active ventilation, passive flushing, contrasting microbial populations, or some combination of these. Additional work will be required to determine the relative importance of these different factors. However, the ranges of variation for all measured parameters were such that it would be difficult to unambiguously identify the 'signature' of a megafaunal burrow opening in the flux data from an individual 'blind' chamber deployment made using an autonomous lander. The ranges of variation demonstrate that sediment-water fluxes at the study site are not spatially uniform, and that megafaunal burrows contribute to this heterogeneity. Similar conclusions have recently been drawn from a biogeochemical study of the deep-sea floor in the Panama Basin (Aller et al. 1998), and the same is likely to be true for any bioturbated marine sediment.

This study includes data from a total of 45 individual benthic chamber deployments, a much larger dataset than available to most previous workers. Indeed, because of time or logistical constraints, some benthic chamber studies lack even the level of replication involved in 1 of our 5-chamber experiments. The effort expended in modelling the internal dynamics of benthic chambers under idealized conditions needs to be complemented by a greater understanding of how measured flux rates are influenced by the natural heterogeneity of the sea floor.

Acknowledgements. We are grateful for the essential field assistance provided by the dive teams of UMBS Millport and DML Oban. Special thanks are owed to Ken Cameron, Jon Chamberlain and Hugh Brown (UMBS Millport). Roy Bowers and Drew Connolly constructed the benthic chambers. We also thank Ivan Ezzi, Martyn Harvey, Ken Jones, Don Kirkwood, Julian Overnell, Paul Provost and Dave Smallman for help with solute analyses, and Steve Malcolm for discussion and suggestions. This work was financed by Research Commission AE1205 from the Ministry of Agriculture, Fisheries and Food, UK

\section{LITERATURE CITED}

Aller RC (1982) The effects of macrobenthos on chemical properties of marine sediment and overlying water. In: McCall PL, Tevesz MJS (eds) Animal-sediment relations. The biogenic alteration of sediments. Plenum Press, New York, p 53-102

Aller RC (1988) Benthic fauna and biogeochemical processes in marine sediments: the role of burrow structures. In: Blackburn TH, Sørenson J (eds) Nitrogen cycling in coastal marine environments. John Wiley \& Sons Ltd, Chichester, p 301-338

Aller RC, Hall POJ, Rude PD, Aller JY (1998) Biogeochemical heterogeneity and suboxic diagenesis in hemipelagic sediments of the Panama Basin. Deep-Sea Res 45:133-165

Anderson LG, Hall POJ, Iverfeldt $A$, Rutgers van der Loeff MM, Sundby B, Westerlund SFG (1986) Benthic respiration measured by total carbonate production. Limnol Oceanogr 31:319-329

Arp AJ, Hansen BM, Julian D (1992) Burrow environment and coelomic fluid characteristics of the echiuran worm Urechis caupo from populations at three sites in northern California. Mar Biol 113:613-623

Atkinson RJA (1986) Mud-burrowing megafauna of the Clyde Sea area. Proc R Soc Edinb 90 Sect B (Biol Sci):351-361

Atkinson RJA, Nash RDM (1990) Some preliminary observations on the burrows of Callianassa subterranea (Montagu) (Decapoda: Thalassinidea) from the west coast of Scotland. J Nat Hist 24:403-413 
Barbanti A, Ceccherelli VU, Frascari F, Rosso G, Reggiani G (1992) Nutrient release from sediments and the role of bioturbation in the Goro Lagoon (Italy). Sci Total Environ 1992 (Suppl):475-487

Berelson WM, Hammond DE (1986) The calibration of a new free-vehicle benthic flux chamber for use in the deep sea. Deep-Sea Res 33:1439-1454

Buchholtz-ten Brink MR, Gust G, Chavis D (1989) Calibration and performance of a stirred benthic chamber. Deep-Sea Res 36:1083-1101

Clavero V, Fernández JA, Xavier Niell F (1992) Bioturbation by Nereis sp. and its effects on the phosphate flux across the sediment-water interface in the Palmones River estuary. Hydrobiologia 235/236:387-392

Davies JM (1975) Energy flow through the benthos in a Scottish sea loch. Mar Biol 31:353-362

Edwards A, Sharples F (1986) The Scottish sea lochs: a catalogue. Scottish Marine Biological Association, Nature Conservancy Council

Forja JM, Gómez-Parra A (1998) Measuring nutrient fluxes across the sediment-water interface using benthic chambers. Mar Ecol Prog Ser 164:95-105

Forster S, Graf G (1995) Impact of irrigation on oxygen flux into the sediment: intermittent pumping by Callianassa subterranea and 'piston-pumping' by Lanice conchilega. Mar Biol 123:335-346

Glud RN, Gundersen JK, Revsbech NP, Jørgensen BB, Huettel $M$ (1995) Calibration and performance of the stirred flux chamber from the benthic lander Elinor. Deep-Sea Res 42:1029-1042

Glud RN, Forster S, Huettel M (1996) Influence of radial pressure gradients on solute exchange in stirred benthic chambers. Mar Ecol Prog Ser 141:303-311

Grasshoff K (1983) Determination of oxygen. In: Grasshoff K, Ehrhardt M, Kremling K (eds) Methods of seawater analysis, 2nd edn. Verlag Chemie, Weinheim, p 61-72

Howson CM, Connor DW, Holt RHF (1994) The Scottish sealochs - an account of surveys undertaken for the Marine Nature Conservation Review (Contractor: University Marine Biological Station, Millport). Joint Nature Conservation Committee Report No. 164 (Marine Nature Conservation Review Report MNCR/SR/27)

Huettel M, Gust G (1992) Solute release mechanisms from confined sediment cores in stirred benthic chambers and flume flows. Mar Ecol Prog Ser 82:187-197

Hughes DJ, Atkinson RJA (1997) A towed video survey of megafaunal bioturbation in the north-eastern Irish Sea. J Mar Biol Assoc UK 77:635-653

Hughes DJ, Ansell AD, Atkinson RJA (1994) Resource utilization by a sedentary surface deposit feeder, the echiuran worm Maxmuelleria lankesteri. Mar Ecol Prog Ser 112: $267-275$

Hughes DJ, Ansell AD, Atkinson RJA (1996) Sediment bioturbation by the echiuran worm Maxmuelleria lankesteri (Herdman) and its consequences for radionuclide dispersal in Irish Sea sediments. J Exp Mar Biol Ecol 195: 203-220

Hughes DJ, Atkinson RJA, Ansell AD (1999) The annual cycle of sediment turnover by the echiuran worm Maxmuelleria lankesteri (Herdman) in a Scottish sea loch. J Exp Mar Biol Ecol 238:209-223

Jahnke RA, Christiansen MB (1989) A free-vehicle benthic chamber instrument for sea floor studies. Deep-Sea Res $36: 625-637$
Kirkwood DS (1992) Stability of solutions of nutrient salts during storage. Mar Chem 38:151-164

Koike I, Mukai H (1983) Oxygen and inorganic nitrogen contents and fluxes in burrows of the shrimps Callianassa japonica and Upogebia major. Mar Ecol Prog Ser 12: $185-190$

Malan DE, McLachlan A (1991) In situ benthic oxygen fluxes in a nearshore coastal marine system: a new approach to quantify the effect of wave action. Mar Ecol Prog Ser 73: $69-81$

Nickell LA (1992) Deep bioturbation in organically enriched marine sediments. PhD thesis, University of London.

Nickell LA. Atkinson RJA (1995) Functional morphology of burrows and trophic modes of three thalassinidean shrimp species, and a new approach to the classification of thalassinidean burrow morphology. Mar Ecol Prog Ser 128: $181-197$

Nickell LA, Atkinson RJA, Hughes DJ, Ansell AD, Smith CJ (1995a) Burrow morphology of the echiuran worm Maxmuelleria lankesteri (Echiura: Bonelliidae) and a brief review of burrow structure and related ecology of the Echiura. J Nat Hist 29:871-885

Nickell LA, Hughes DJ, Atkinson RJA. (1995b) Megafaunal bioturbation in organically-enriched Scottish sea lochs. In: Eleftheriou A, Ansell AD, Smith CJ (eds) Biology and ecology of shallow coastal waters. Proceedings 28th European Marine Biological Symposium, Iraklio, Crete, 1993. Olson \& Olson, Fredensborg, p 315-322

Overnell J, Edwards A, Grantham BE, Harvey SM, Jones KJ, Leftley JW, Smallman DJ (1995) Sediment-water column coupling and the fate of the spring phytoplankton bloom in Loch Linnhe, a Scottish fjordic sea loch. Sediment processes and sediment-water fluxes. Estuar Coast Shelf Sci 41:1-19

Overnell J, Harvey SM, Parkes RJ (1996) A biogeochemical comparison of sea loch sediments. Manganese and iron contents, sulphate reduction and oxygen uptake rates. Oceanol Acta 19:41-55

Pemberton GS, Risk MJ, Buckley DE (1976) Supershrimp: deep bioturbation in the Strait of Canso, Nova Scotia. Science 192:790-791

Rutgers van der Loeff $M M$, Anderson LG, Hall POJ, Iverfeldt A, Josefson AB, Sundby B, Westerlund SFG (1984) The asphyxiation technique: an approach to distinguishing between molecular diffusion and biologically mediated transport at the sediment-water interface. Limnol Oceanogr 29:675-686

Tengberg A, De Bovee F, Hall P, Berelson W, Chadwick D, Ciceri G, Crassous P, Devol A, Emerson S, Gage J, Glud R, Graziottini F, Gundersen J, Hammond D, Helder W, Hinga K, Holby O, Jahnke R, Khripounoff A, Lieberman S, Nuppenau $V$, Pfannkuche O, Reimers C, Rowe G, Sahami A, Sayles F, Schurter M, Smallman D, Wehrli B, De Wilde P (1995) Benthic chamber and profiling landers in oceanography - a review of design, technical solutions and functioning. Progr Oceanogr 35:253-294

Waslenchuk DG, Matson EA, Zajac RN Dobbs FC, Tramontano JM (1983) Geochemistry of burrow waters vented by a bioturbating shrimp in Bermudian sediments. Mar Biol 72:219-225

Ziebis W, Forster S, Huettel M, Jorgensen BB (1996) Complex burrows of the mud shrimp Callianassa truncata and their geochemical impact in the sea bed. Nature 382: $619-622$

Submitted: May 10, 1999; Accepted: August 9, 1999

Proofs received from author(s): March 13, 2000 